\title{
Surface Modification of Hydrophobic Polymers for Improvement of Endothelial Cell-Surface Interactions
}

\author{
A. Dekker ${ }_{,}^{a *}$ K. Reitsma, ${ }^{a}$ T. Beugeling, ${ }^{a}$ A. Bantjes,${ }^{a}$ J. Feijen, ${ }^{a}$ C. J. Kirkpatrick ${ }^{b}$ \\ \& W. G. van Aken ${ }^{\alpha}$ \\ ${ }^{a}$ Faculty of Chemical Technology, University of Twente, Enschede, The Netherlands \\ ${ }^{b}$ Institute of Pathology, Technical University of Aachen, Klinikum der RWTH, Pauwelsstraße, D-5100 Aachen, \\ Germany
}

\begin{abstract}
The aim of this study is to improve the interaction of endothelial cells with polymers used in vascular prostheses. Polytetrafluoroethylene (PTFE; Teflon) films were treated by means of nitrogen and oxygen plasmas. Depending on the plasma exposure time, modified PTFE surfaces showed water-contact angles of $15-58^{\circ}$ versus $96^{\circ}$ for unmodified PTFE. Electron spectroscopy in chemical analysis (ESCA) measurements revealed incorporation of both nitrogenand oxygen-containing groups into the PTFE surfaces, dependent on the plasma composition and exposure time. In-vitro biological evaluation of unmodified and modified PTFE surfaces showed that human endothelial cells, seeded from $20 \%$ human serum-containing culture medium, adhered well on to modified PTFE surfaces, but not on to unmodified films. Adhesion of endothelial cells on to expanded PTFE graft material (Gore-Tex) was also stimulated by plasma treatment of this substrate. On plasma-treated expanded PTFE, the adhering endothelial cells formed a monolayer, which covered the textured surface. The latter observation is important in view of the hemocompatibility of vascular grafts seeded with endothelial cells before implantation.
\end{abstract}

\section{INTRODUCTION}

Synthetic vascular grafts with a relatively large inner diameter ( $>5 \mathrm{~mm}$ ) are successfully employed for replacement or bypassing of stenosed or obstructed arteries. However, the use of small diameter prostheses is limited, predominantly because of thrombotic occlusion. ${ }^{1}$ The ideal blood contacting surface of a prosthesis would be an endothelial lining, because endothelium is the natural nonthrombogenic lining of blood vessels. ${ }^{2}$ Since in humans endothelium does not develop spontaneously on the luminal side of a graft, seeding of autologous endothelial cells during surgery is necessary. ${ }^{1-3}$

* To whom correspondence should be addressed. Present address: Institute of Pathology, Technical University of Aachen, Klinikum der RWTH, Pauwelsstraße, D-5100 Aachen, Germany.
Successful endothelialization of the graft after cell seeding will only occur if the endothelial cells adhere and spread well on to the surface. ${ }^{4}$ However, results of in-vitro studies in our laboratory on the interactions of human endothelial cells with polymers revealed that endothelial cells show a poor adhesion on to hydrophobic materials. ${ }^{4}$ Dacron $^{\circledR}$ (polyethyleneterephthalate, PET) and Teflon ${ }^{\circledR}$ (polytetrafluoroethylene, PTFE), which are widely used for the production of vascular grafts, are such hydrophobic materials. Endothelial cells adhere well on to moderately water-wettable polymers. ${ }^{4}$ In view of this, a possible method for making hydrophobic, vascular graft materials more suitable for endothelial cell adhesion is to increase the wettability of the surface.

In the present study this concept was applied to polytetrafluoroethylene (PTFE) fillms and to expanded PTFE graft material. PTFE surfaces were 
modified by gas plasma (glow discharge) treatment which made them more wettable. The effects of this treatment on the surface composition, surface charge, and adhesion of human endothelial cells were investigated.

\section{MATERIALS AND METHODS}

\section{Plasma treatment}

PTFE films (polytetrafluoroethylene; $13 \mathrm{~cm} \times$ $13 \mathrm{~cm} \times 0.10 \mathrm{~mm}$ ) (Fluorplast Nederland BV, Raamdonksveer, The Netherlands) were cleaned ultrasonically for 30 minutes in a $1 \%(\mathrm{v} / \mathrm{v}) \mathrm{dc}-$ tergent solution (RBS 25) (Hicol, Oud-Beierland, The Netherlands) and extensively rinsed with distilled water and absolute ethanol (Merck, Darmstadt, Germany). Expanded PTFE patch (ePTFE; soft tissue Gore-Tex) (W. L. Gore and Associates, Flagstaff, USA) was used as received. The gas plasma (glow discharge) treatment was performed in a Plasmafab 505 barrel plasma reactor (Electrotech, Bristol, UK). The PTFE surfaces were placed $25 \mathrm{~mm}$ above the inner electrode, immediately above the position of the generated plasma. The gases used were oxygen $(>99.5 \%(\mathrm{v} / \mathrm{v}))$ (Hoekloos, Schiedam, The Netherlands) and nitrogen $(>99.9990 \%(\mathrm{v} / \mathrm{v}))$ (Hoekloos). The pressure inside the plasma chamber was kept at $20 \pm 1 \mathrm{~Pa}$ for the nitrogen plasma and at $9 \pm 1 \mathrm{~Pa}$ for the oxygen plasma. The electrode power was (unless otherwise mentioned) $250 \mathrm{~W}$ for the nitrogen plasma and $300 \mathrm{~W}$ for the oxygen plasma. The gas flow of both gases was chosen in such a way that the above mentioned plasma pressures werc realized. Atmospheric pressure in the plasma chamber was restored by flushing with argon (> 99.997\% (v/v)) (Hoekloos). The treated PTFE samples were stored in hyperfiltrated water at room temperature before being used for experiments.

\section{Contact angle measurement}

Contact angles were determined by means of the captive bubble method ${ }^{5} 20-24$ hours after plasma treatment.

\section{Zeta-potential}

The zeta-potentials of the polymer surfaces were determined from streaming potential measurements in a flat plate system. ${ }^{6,7}$

\section{ESCA}

ESCA measurements were performed with a Kratos XSAM 800 (Kratos Analytical, Manchester, UK). For etching surfaces, the system was equipped with a differential pumped microbeam argon ion gur. Electron spectroscopy for chemical analysis (ESCA) measurements of the PTFE films were performed with $\mathrm{X}$-rays from an $\mathrm{Mg}$ source $(1253.6 \mathrm{eV})$ at a take-off angle of $30^{\circ}$ between the polymer surface and the analyzer. For quantitative analysis, detail scans (steps of $0.05 \mathrm{eV}$ ) were made of the $\mathrm{C} 1 \mathrm{~s}, \mathrm{~F}$ Is, $\mathrm{O} 1 \mathrm{~s}$, and $\mathrm{N}$ is peaks, at medium resolution $(20 \mathrm{eV}$ pass energy) and low magnification $\left(0.75 \mathrm{~cm}^{2}\right.$ spot size). Integration of the peaks, calculation of the surface concentration of the various elements, and X-ray-satellite subtraction were performed with standard software (DS 800) supplied by the manufacturer. PTFE samples, treated for 600 seconds with nitrogen or oxygen plasma, were etched for depth profiling with $\mathrm{Ar}^{+}$ions at a rate corresponding to $0.5 \mathrm{~mm}$ per minutc for $\mathrm{Ta}_{2} \mathrm{O}_{5}$.

\section{Cell adhesion}

Human endothelial cells were isolated from the umbilical vein according to the method of Willems et $a l^{8}$ and were cultured as described by Van Wachem et al. ${ }^{*}$ Cell adhesion experiments were performed with unmodified and plasma-treated PTFE films and EPTFE, which were mounted in a test device with 12 wells having test surfaces of $1.5 \mathrm{~cm}^{2}$, essentially as described by Van Wachem $\mathrm{et}$ al. ${ }^{4}$ Endothelial cells, resuspended in $20 \%$ human serum-containing culture medium, were seeded into the wells at a density of $60000 \mathrm{~cm}^{-2}$. After 6 hours the adherent cells were detached by adding a known volume of trypsin solution and the suspended cells were counted in a Buerker chamber.

\section{RESULTS AND DISCUSSION}

Since the luminal surface of vascular grafts is not spontaneously overgrown by endothelium, which is the natural lining of a normal blood vessel, seeding of endothelial cells has been proposed to obtain endothelialization. A prerequisite for successful cell seeding is an optimal adhesion of endothelial cells on to the graft surface. The present study was undertaken to investigate and optimize the adhesion of endothelial cells on to PTFE, which is a 


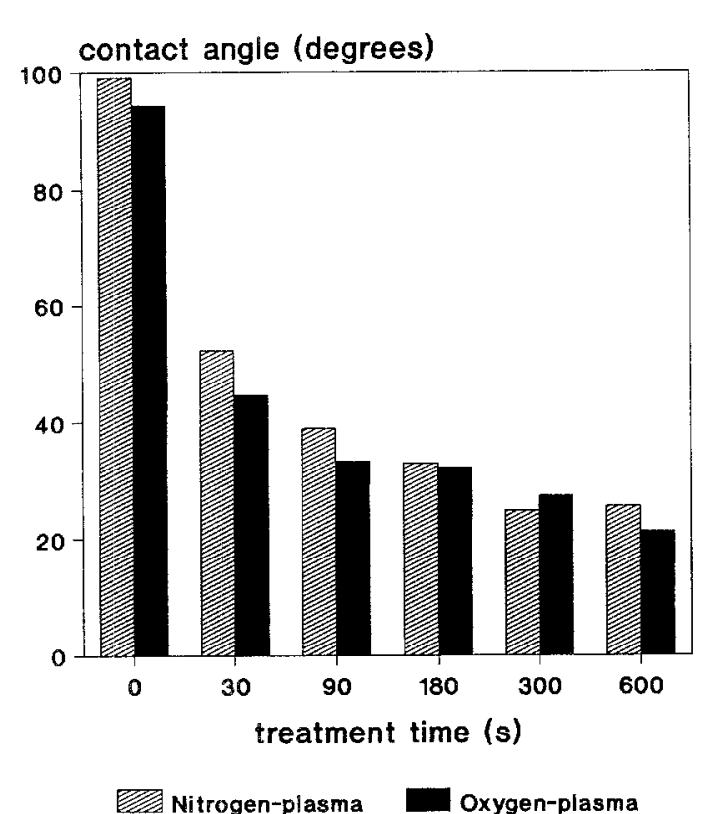

Fig. 1. Relationship between contact angle and treatment time of PTFE films modified by means of nitrogen and oxygen plasma $(n=3)$.

commonly used material for the production of vascular grafts.

Following the suggestion of Van Wachem et al. ${ }^{4}$ that adhesion and proliferation of human endothelial cells are promoted on moderately wettable polymers, we attempted to stimulate the adhesion of endothelial cells by improving the wettability of PTFE surfaces.

\section{Plasma treatment and contact angles}

Plasma treatment using nitrogen or oxygen appeared to be a very effective method of increasing the wettability of PTFE surfaces. Depending on the treatment time, modified PTFE surfaces were prepared with contact angles between 15 and $58^{\circ}$, as unmodified PTFE has a contact angle of $96^{\circ}$ (Fig. 1).

In order to have the possibility of measuring the contact angle of the textured ePTFE patch, we had to compress this material to a flat surface $(543 \mathrm{~K}$, $20 \mathrm{MPa}$ ). Measurements revealed a mean contact angle of $104^{\circ}$.

\section{Zeta-potential}

Further characterization of unmodified PTFE surfaces included zeta-potential and ESCA measurements. In spite of the clear effect of plasma treatment on the wettability of PTFE films, the zeta-potentials of the surfaces were hardly affected by modification. The zeta-potential of unmodified PTFE film was $-28 \mathrm{mV}$, whereas the values of the modified films varied between -23 and $-30 \mathrm{mV}$. Therefore, the differences between the zetapotentials of modified and unmodified PTFE films were relatively small. Moreover, these differences could not be correlated with the contact angles of the films. Therefore, the influence of the zetapotentials of the modified films on the adhesion of endothelial cells to these surfaces seems to be of minor importance. ${ }^{10}$

The unmodified PTFE surfaces had a negative zeta-potential although these surfaces do not contain charged groups. This has also been reported for other uncharged polymers like polystyrene and polyvinylchloride $^{7}$ and is probably caused by specific adsorption of ions to the surface.

\section{ESCA}

In contrast with the results of the zeta-potential measurement, plasma treatment did influence the chemical composition of the PTFE surfaces. Comparison of the C 1s spectra of unmodified and plasma-treated PTFE films showed that the spectra changed upon plasma treatment, depending on the treatment time and plasma gas. Compared to the $C$ 1s spectrum of unmodified PTFE, the spectra of the nitrogen plasma-treated PTFE films showed an increased intensity in the binding energy region of $285-289 \mathrm{eV}$, whereas the spectra of the oxygen plasma-treated PTFE films demonstrated changes in the region of $285-286 \mathrm{eV}$. The intensity in these binding energy regions increased with increasing treatment time. The $\mathrm{C} 1 \mathrm{~s}$ spectra of surfaces treated with one type of plasma (nitrogen or oxygen) were qualitatively the same for the various treatment times, whilst the spectra of films treated with nitrogen and oxygen differed qualitatively. These results suggest that, irrespective of the treatment time, the same modification processes occur when a particular plasma gas is used, but that these processes are somewhat different for nitrogen and oxygen plasma.

Analysis of detail spectra of $\mathrm{O} 1 \mathrm{~s}$ and $\mathrm{N} 1 \mathrm{~s}$ regions revealed that unmodified PTFE did not have nitrogen- or oxygen-containing groups, but plasma-treated surfaces contained such groups. The changes in the $\mathrm{C}$ 1s spectra could be related to changes in the detail scans of the $\mathrm{O} 1 \mathrm{~s}$ and $\mathrm{N} 1 \mathrm{~s}$ regions. The increased wettability of treated PTFE films could be ascribed to this nitrogen and oxygen 


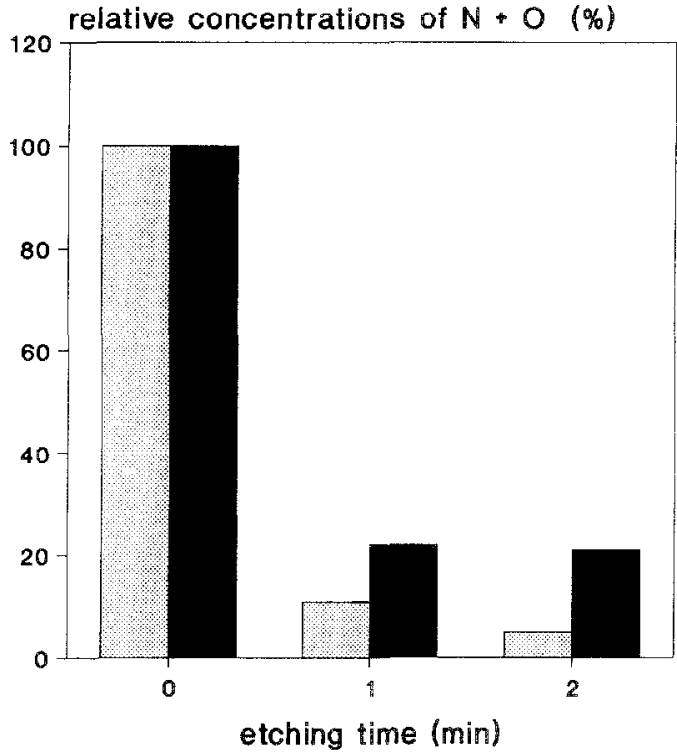

ॠ Nitrogen-plasma $\square$ Oxygenuplasma

Fig. 2. The relative surface concentrations of the sum of atomic nitrogen and oxygen of plasma-treated PTFE films after etching with argon ions for various time intervals. Treatments with nitrogen and oxygen plasma were performed for $600 \mathrm{~s}$ at 21 and $14 \mathrm{~Pa}$, and 180 and $220 \mathrm{~W}$, respectively.

incorporation into the surface, for there was a strong relationship between the relative surface concentrations of nitrogen and oxygen atoms of treated PTFE films and the contact angles measured at these surfaces.

ESCA analysis of unmodified ePTFE patches revealed the presence of carbon and fluorine in the surface, and only negligible amounts of oxygen and nitrogen could be detected. These data and the hydrophobic nature of ePTFE (contact angle $104^{\circ}$ ) indicate that these patches are not already surface treated by the manufacturer.

The thickness of the modified surface layer of plasma-treated PTFE films was determined by etching with $\mathrm{Ar}^{+}$ions at a rate corresponding to $0.5 \mathrm{~nm}$ per minute for $\mathrm{TA}_{2} \mathrm{O}_{5}$. It is assumed that the etching rate for PTFE is about the same as for $\mathrm{Ta}_{2} \mathrm{O}_{5}$. When $0.5 \mathrm{~nm}$ of the modified surface was removed most of the incorporated nitrogen and oxygen atoms was removed (Fig. 2). The surface modifications induced by treatment with nitrogen plasma were more restricted to the surface than those induced by treatment with oxygen plasma. After etching a layer of $1 \mathrm{~nm}$ from oxygen plasmatreated PTFE films, $20 \%$ of incorporated nitrogen and oxygen atoms was still present in the surface, while after etching $1 \mathrm{~nm}$ from nitrogen plasmatreated PTFE films, only 5\% of the incorporated nitrogen and oxygen atoms remained.
Thus plasma treatment of PTFE films resulted in a very superficial modification of the surface (of the order of $1 \mathrm{~nm}$ ). This is superficially of importance with regard to modification of EPTFE vascular grafts to improve adhesion of endothelial cells, because such a modification should not affect the porosity and the mechanical properties of the graft.

\section{Biological evaluation}

The influence of plasma treatment of PTEE films on the adhesion of endothelial cells on to these surfaces was evaluated using in-vitro cultured human endothelial cells. During 6 hours, endothelial cells hardly adhered to the unmodified PTFE film, whereas relatively large numbers of cells were detected on plasma-treated PTFE films during this period (Fig. 3). This effect was irrespective of the gas used to generate a plasma. After $6 \mathrm{~h}$ of incubation the number of cells adhered to plasma treated surfaces approximated the number of cells adhered to TCPS, which is known for its excellent cell adhesion properties. ${ }^{4}$ This effect was most evident for PTFE films with contact angles between 20 and $45^{\circ}$. The number of adherent cells on these films was $90-110 \%$ of the number of cells found on TCPS. Modified PTFE surfaces with a contact angle smaller or larger than those of the mentioned range also showed an increased cell adhesion, compared to unmodified PTFE surfaces, but the numbers of adherent cells were less than found on TCPS after $6 \mathrm{~h}$ incubation. These results are in agreement with those of others, who also found an increased adhesion of cells on to more hydrophilic surfaces, obtained by plasma treatment of polymers. compared to unmodified polymers. ${ }^{11-14}$

Plasma treatment of PTFE does not only lead to an increased number of adherent endothelial cells but also causes a pronounced morphological change of these cells. Endothelial cells were well spread on plasma-treated PTFE films, whilst cells adherent to unmodified PTFE were hardly spread. Modified PTFE surfaces outside the contact angle range of $20-45^{\circ}$ sometimes showed detachment of cells. The optimal spreading of endothelial cells on modified PTFE surfaces showing contact angles within the range of $20-45^{\circ}$ strongly suggests that endothelial cells are able to proliferate on these polymerio surfaces. ${ }^{4}$

In view of the described beneficial effects of plasma treatment of PTFE films on the adhesion and spreading of human endothelial cells, it is logical to study the possibility of modifying Tefion 


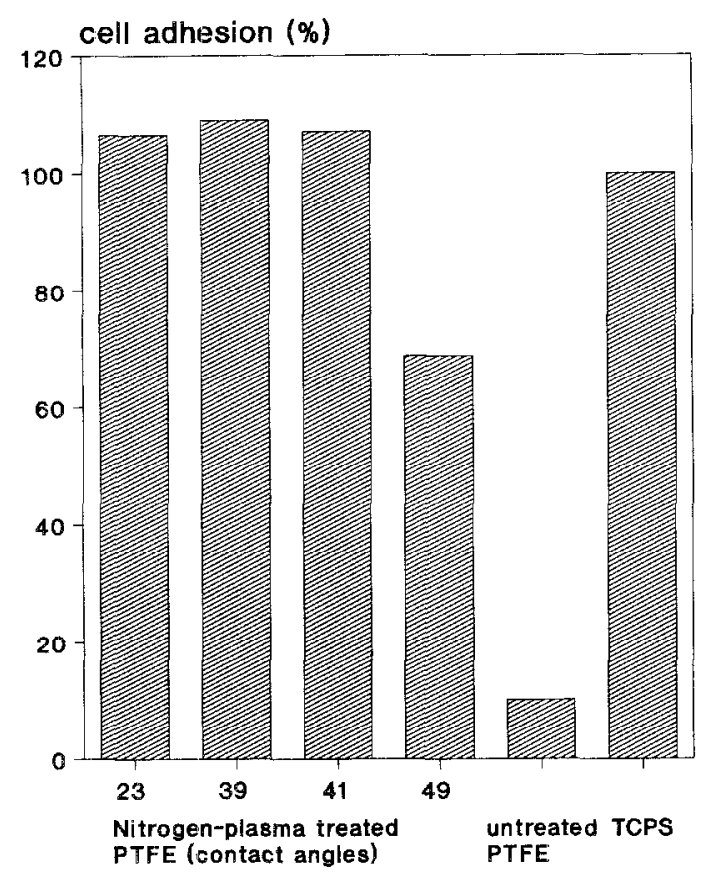

(a)

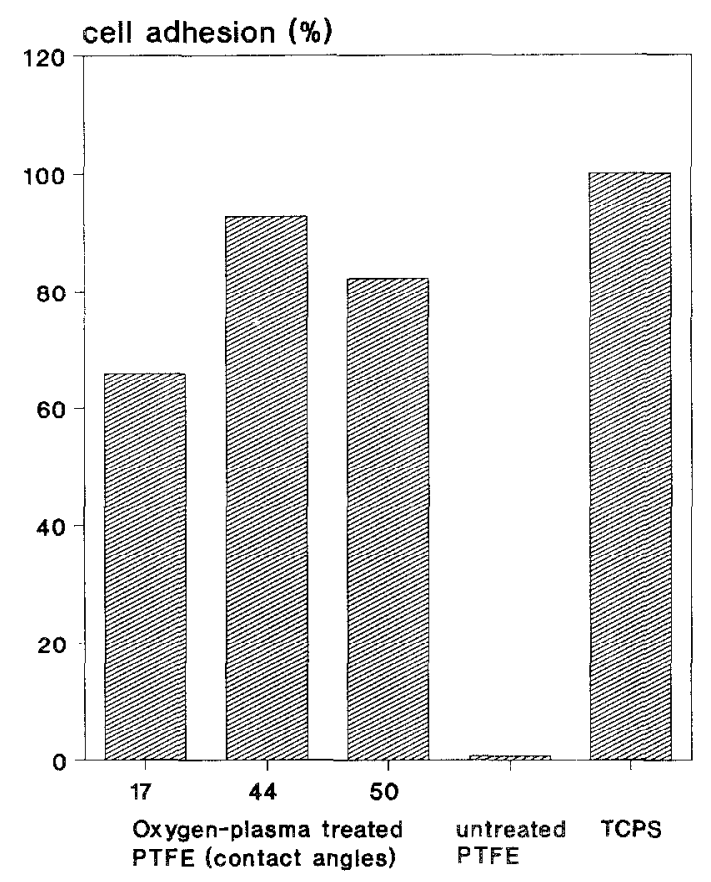

(b)

Fig. 3. Adhesion of human endothelial cells to unmodified (a) nitrogen and (b) oxygen plasma-treated PTFE films and to TCPS, after incubation with a cell suspension for $6 \mathrm{~h}$. Cell adhesion is expressed as a percentage of the adhesion on to TCPS $(n=3)$.

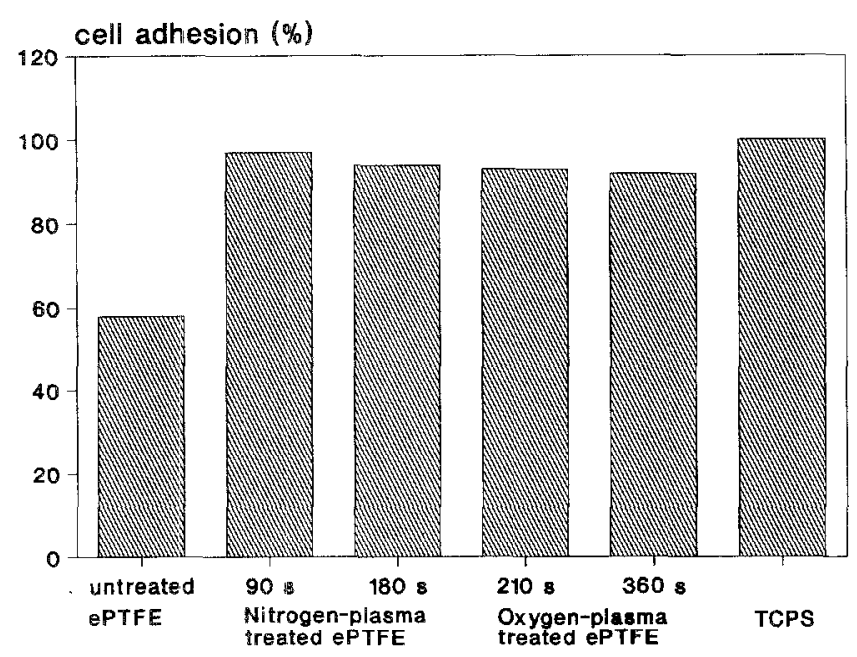

Fig. 4. Adhesion of human endothelial cell to untreated, plasma-treated PTFE films and to TCPS, after incubation with a cell suspension for $6 \mathrm{~h}$. Cell adhesion is calculated relative to the adhesion on to TCPS $(n-3)$. Plasma treatment with nitrogen and oxygen was performed for the indicated times at 21 and $15 \mathrm{~Pa}$, and 180 and $210 \mathrm{~W}$, respectively.

vascular grafts (ePTFE; Gore-Tex) in the same way. Treatment of expanded PTFE patches with oxygen or nitrogen plasma improved adhesion and spreading of endothelial cells, compared to unmodified patches (Fig. 4). Adhesion of endothelial cells on to the modified graft material was comparable to the adhesion on to TCPS which indicates the feasibility of plasma modification of ePTFE to improve endothelial cell adhesion. The difference in cell adhesion between modified and unmodified ePTFE patches was not as large as observed in the case of adhesion experiments with modified and unmodified PTFE films. This is probably due to the porous structure of the surface of ePTFE patches which allows the cells to attach to the unmodified material. Though the surface of the ePTFE graft material is porous (internodal distance: $22 \mu \mathrm{m}$ ), endothelial cells spread completely on the plasmatreated graft material and covered the pores. Cell spreading on the modified EPTFE patches was much like the spreading of endothelial cells on the luminal surface of a preclotted EPTFE graft used in canine experiments. ${ }^{15,16}$ These latter observations are also important in view of hemocompatibility of seeded grafts, since platelet deposition experiments showed only a negligible platelet deposition on to surfaces completely covered with endothelial cells. ${ }^{17}$

In conclusion, in the present study plasma treatment of PTFE with nitrogen and oxygen appeared to be a powerful method to increase the wettability of the surface. These plasma-treated PTFE surfaces showed excellent cell adhesion properties. It is likely that the plasma-treatment method can also be applied to other hydrophobic polymers which show poor interaction with endothelial cells. ${ }^{11,13}$ These may be polymers which are already in use for the production of vascular grafts or are under development now and will be used in the future. 


\section{REFERENCES}

1. Callow, A. D., Historical overview of experimental and clinical development of vascular grafts. In Biological and Synthetic Vascular Prostheses, ed. J. C. Stanley, W. E. Burkel, S. M. Lindenauer, R. H. Bartlett \& J. G. Turcotte. Grune and Stratton, New York, 1982, p. 11.

2. Herring, M. B., Endothelial seeding of blood flow surfaces. In Vascular Grafting, Clinical Applications and Techniques, ed. C. B. Wright. John Wright PSG Inc., Boston, 1983, p. 275.

3. Berger, K., Sauvage, L. R., Rao, A. M. \& Wood, S. J., Healing of arterial prostheses in man: its incompleteness. Ann. Surg., 175 (1972) 118.

4. Van Wachem, P. B., Beugeling, T., Feijen, J., Bantjes, A., Detmers, J. P. \& Van Aken, W. G., Interaction of cultured human endothelial cells with polymeric surfaces of different wettabilities. Biomaterials, 6 (1985) 403.

5. Andrade, J. D., Smith, L. M. \& Gregonis, D. E., The contact angle and interface energetics. In Surface and Interfacial Aspects of Biomedical Polymers, Vol. 1, Surface Chemistry and Physics, ed J. D. Andrade. Plenum Press, New York, 1985, p. 249.

6. Van Wagenen, R. A. \& Andrade, I. D., Flat plate streaming potential investigations: hydrodynamics and electrokinetic equivalency. $J$. Colloid Interface Sci., 76 (2) (1980) 305.

7. Yan Wagenen, R. A., Coleman, D. L., King, R. N., Triolo, P., Brostrom, L., Smith, L. M., Gregonis, D. E. \& Andrade, J. D., Streaming potential investigations: polymer thin films. J. Colloid Interface Sci., 84 (1) (1981) 155.

8. Willems, Ch., Astaldi, G. C. B., de Groot, Ph. D., Jansen, M. C., Gonsalves, M. D., Zeijlemaker, W. P., van Mourik, J. A. \& van Aken, W. G., Media conditioned by cultured vascular endothelial cells inhibit the growth of vascular smooth muscle cells. Exp. Cell Res., 139 (1982) 191.

9. Van Wachem, P. B., Reinders, J. H., van Buul-Wortelboer, M. F., de Groot, Ph. G., van Aken W. G. \& van Mourik,
J. A., Von Willebrand factor in cultured human yascular endothelial cells from adult and umbilical cord arteries and veins. Thromb. Haemost., 56 (1986) 189.

10. Van Wachem, P. B., Hogt, A. H., Beugeling, T., Fejen, Bantjes, A. Detmers, \& van Aken, W. G., Adhesion of cultured human endothelial cells onto methacrylate polymers with varying surface wettability and charge. Biomaterials, $8(1988) 323$.

11. Chinn, I. A., Horbett, T. A., Ratner, B. D., Schway, M. B., Haque, Y., \& Hauschka, S. D., Enhancement of serum fibronectin adsorption and the clonal plating efficiencies of Swiss mouse 3T3 fibroblast and MM14 mouse myoblast cells on polymer substrates modified by radio frequency plasma deposition. $J$. Colloid 7 nterface Sci., 127 (1989) 67.

12. Van Wadiem, P. B., Interactions of culured buman endothelial cells with polymeric surfaces. PhD thesis. University of Twente, Enschede, The Netherlands, 1987, p. 39.

13. Pratt, K. J., Williams, S. K. \& Jarrell, B. E., Enhanced adherence of human adult endotbelial cells to plasma discharge modified polyethylene terephthalate. $J$. Biomed. Mater. Res., 23 (1989) 1131.

14. Klee, D., Breuers, W., Bilo-Jung, M., Mittermayer, C. \& Hocker, H., Modifizierung von polymeroberflaechen zur erhoehung der zelladhaesion. Die Angewandte Makromolekul. Chem., 166/167 (1989) 179 .

15. Plate, G., Hollier, L. H., Fowl, R. J., Sande, I. R. \& Kaye, M. P., Endothelial seeding of venous prostheses. Surgery; 96 (5) (1984) 929.

16. Pearce, W. H., Rutherford, R. B., Whitehill, T.A., Rosales, C., Bell, K. P., Patt, A. \& Ramalanjaona, G. Successful endothelial seeding with omentally derived microvascular endothelial cells. J. Vase. Surg., 5(1) (1987) 203.

17. Dekker, A., Poot, A., Beugeling, T., Bantjes, A. \& van Aken, W. G., The effect of vascular cell seeding on platelet deposition in an in vitro capillary perfusion model Thromb. Haemost., 61 (3) (1989) 402. 